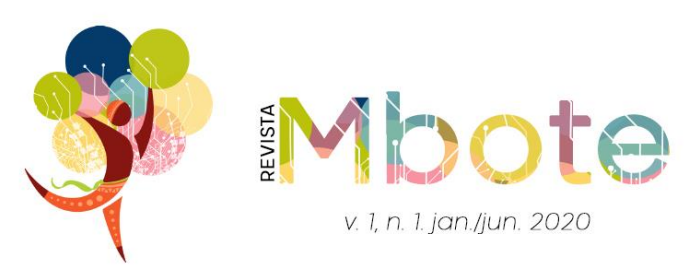

\title{
O CAMINHO A PERCORRER NA EVOLUÇÃO DE DESTINO TURÍSTICO CONSOLIDADO PARA DTI: O CASO DO MUNICÍPIO DE PORTO SEGURO-BA.
}

\author{
Gilvason da Costa LEITE ${ }^{1}$; Clediane Nascimento SANTOS ${ }^{2}$
}

\begin{abstract}
Resumo: Este estudo descritivo com abordagem qualitativa tem como objetivo principal analisar o potencial existente no Município de Porto Seguro, tendo a sede de Porto Seguro e o distrito de Arraial d'Ajuda como mote de pesquisa, visando à possibilidade da transformação de um Destino Turístico Consolidado em Destino Turístico Inteligente na Costa do Descobrimento. Esta pesquisa caracteriza-se como um estudo de caso, tendo como procedimentos metodológicos de coleta de informações, o levantamento bibliográfico e documental, bem como a técnica da observação direta sistemática. Os resultados encontrados em relação ao potencial do município de Porto Seguro para uma possível transformação em DTI demonstram que a infraestrutura e equipamentos existentes no destino poderiam se adequar ao modelo de DTI, porém, pode-se constatar que somente a infraestrutura presentes não é capaz de atender os pilares que compõem os diferentes exemplos de DTI.
\end{abstract}

Palavras-chave: Turismo. Gestão. Destinos Turísticos Inteligentes. Porto Seguro.

\section{THE WAY TO GO IN THE EVOLUTION OF A CONSOLIDATED TOURIST DESTINATION TO DTI: THE CASE OF PORTO SEGURO - BA.}

\begin{abstract}
This study described the qualitative approach has as main objective to analyze the potential existing in the city of Porto Seguro, with the headquarters of Porto Seguro and the district of Arraial d'Ajuda being the place of research, using the possibilities of transforming a Consolidated Tourist Destination into a Smart Tourist Destination(STD) on the "Costa do Descobrimento". This research describes as a case of study, with methodological procedures for collecting information, the bibliographic and documentary survey, as well as a technique of systematic direct observation. The results found in relation to the potential of the City of Porto Seguro and the district of Arraial d'Ajuda for a possible transformation into a STD demonstrate that the infrastructure and equipment existing at the destination could be suitable for the STD model, however, they could also show that only the present infrastructure is not enought to meet the bases that make up the different examples of STD.
\end{abstract}

Keywords: Tourism. Management. Smart Tourist Destination. Porto Seguro.

\section{INTRODUÇÃO}

O turismo no Município de Porto Seguro tem um papel fundamental para o setor econômico, o que demanda uma atenção maior por parte dos gestores para o desenvolvimento do destino, visto que, a atividade turística se constitui em um conjunto de ações que depende da interação de vários agentes responsáveis pelo

\footnotetext{
${ }^{1}$ Bacharel em Turismo pela Universidade do Estado da Bahia (UNEB), Campus XVIII. E-mail: gilcostafm@hotmail.com

2 Doutorado em Geografia pela Universidade Estadual Paulista "Julio de MEsquita Filho" - Pres Prudente, Brasil (2018).

Professora Adjunto do curso de Hotelaria da Universidade Federal do Rio Grande, Brasil. E-mail: clensantos@furg.br
} 
turismo no município, e essas atuações se juntam para resultar por um só objetivo, que é o desenvolvimento do destino (BENI, 1998).

Esta pesquisa tratou-se de um estudo de caso no Município de Porto Seguro na Bahia e tem como tema Destinos Turísticos Inteligentes - DTIs que através da tecnologia e inovação buscam ser mais competitivo, de forma sustentável e assim planejar decisões para melhorar a qualidade da experiência turística no destino (SEGITTUR, 2015).

Assim, surge uma nova era do turismo marcada pela competitividade, os avanços tecnológicos e por um turista que está constantemente conectado a internet buscando e sendo influenciado por informações relacionadas às viagens e os atrativos dos mais diversos destinos turísticos. Com isso, percebe-se a necessidade do Município de Porto Seguro se posicionar em meio aos demais destinos, tornandose uns dos Destinos Turísticos Inteligentes no âmbito nacional e internacional.

A relevância desse artigo é devido à carência de estudos científicos voltados para o destino de Porto Seguro como um destino turístico inteligente. De tal modo, converter um Destino Turístico Tradicional consolidado em Destino Turístico Inteligente é desenvolver uma estratégia de revalorização por meio da tecnologia, inovação, acessibilidade e sustentabilidade.

O município de Porto Seguro é um dos destinos turísticos que mais se destaca no Estado da Bahia. Sendo assim, os estudos das diretrizes apresentadas pela SEGITTUR (2025) poderão gerar vantagens competitivas, no mercado turístico, frente a outros destinos tradicionais, desenvolvendo um ambiente inovador e mais sustentável na questão ambiental, sociocultural e econômica. As melhorias que um DTI proporciona irão refletir não somente na infraestrutura para o turista, como também para os residentes.

Para tanto o objetivo geral é analisar o potencial existente no Município de Porto Seguro, tendo a sede de Porto Seguro e o distrito de Arraial d'Ajuda como locais de 
pesquisa, visando à possibilidade da transformação de um Destino Turístico Consolidado em Destino Turístico Inteligente na Costa do Descobrimento.

\section{O NOVO TURISTA E A COMPETITIVIDADE NOS DESTINOS}

Percebe-se que os destinos turísticos têm investido no relacionamento com o turista na internet, principalmente nas redes sociais. Quando se diz que um destino deve estar em contato com seu público isso inclui a presença online. Não é somente estar nas mídias sociais, mas saber usá-las de maneira estratégica e efetiva. $O$ planejamento e a leitura do seu público no ambiente virtual são estratégias valiosas, falar a mesma linguagem que seus visitantes, saber administrar a oferta e adequarse à demanda. A internet na atualidade é o contato mais próximo, rápido e que pode evitar danos negativos à imagem de um destino, através de um diagnóstico instantâneo do perfil do seu visitante.

Uma multiplicidade de ferramentas influencia o turista a ser mais independente na escolha de um destino para visitar como os portais de reservas online, tais como, (Decolar, Booking, Expedia, dentre outros), navegadores de buscas (Google, Mozila,), redes sociais (Instagram, Facebook, Twitter, WhatsApp, dentre outros), portais de avaliação (TripAdvisor), sistema de gestão de vendas (Omnibees) e site de comparação de preços ( Trivago).

Segundo Monaco (2018) surge uma nova demanda: a geração Z, um novo perfil de consumidores. São considerados nativos digitais, pessoas que nasceram com a tecnologia na palma da mão, influenciadas pela era digital desde sempre, desconhecem o mundo real e determina um comportamento que está ligado a uma busca descontrolada por informações para comprar, verificar comentários, fazer reservas e contatos nas redes sociais. Acredita-se que em 2020 essa geração serão os viajantes mais presentes no mercado do segmento do turismo.

A geração $Z$ tem características parecidas com a geração $Y$, que foi a fase da evolução tecnológica, dos computadores e da internet. Porém, o que diferencia é a 
necessidade de manter-se conectado, passando horas por dia online e tem a atenção voltada para o aparelho smartphone (MANDER, 2018).

Em um estudo produzido pela agência We Are Social $(2018)^{1}$ aponta que a rede social favorita entre os brasileiros é o YouTube (95\%), seguido pelo Facebook (90\%) e WhatsApp (89\%). Já a liderança no cenário global é ocupada pelo Facebook, com 2,27 bilhões de usuários ativos, em segundo e terceiro lugar estão, respectivamente, o YouTube (1,900 milhões) e o WhatsApp (1.500 milhões). O relatório também indica que $61 \%$ dos internautas do país acessam redes sociais via dispositivo móvel (celular ou tablet) ficando em média, três horas e 34 minutos por dia nas redes sociais.

Ainda de acordo com a We Are Social (2019) o número de brasileiros que têm acesso à internet aumentou em 10 milhões, o que representa um crescimento de $7,2 \%$ referente ao ano de 2018, sendo um total de 140 milhões de usuários nas mídias sociais. Em 2019 o uso da internet atingiu 70\% da população brasileira que aparece com 57\% acima da média global. O Brasil aparece atrás apenas das Filipinas em relação às horas gastas na internet totalizando 9 horas e 29 minutos por dia online.

As pesquisas realizadas nos anos de 2015 e 2016 pelo Serviço Brasileiro de Apoio às Micro e Pequenas Empresas - SEBRAE em parceria com a Secretaria de Cultura e Turismo - SECTUR e o Porto Seguro Convention Bureau sobre a demanda potencial do destino Porto Seguro apresentam um percentual bastante significativo em relação à influência do uso da tecnologia como instrumento de decisão de compra conforme o gráfico 1.

\footnotetext{
${ }^{1}$ Agência especializada em social media. Empresa com sede no Reino Unido, Londres. 
Gráfico 1 - Fontes de pesquisa para escolha do próximo destino.

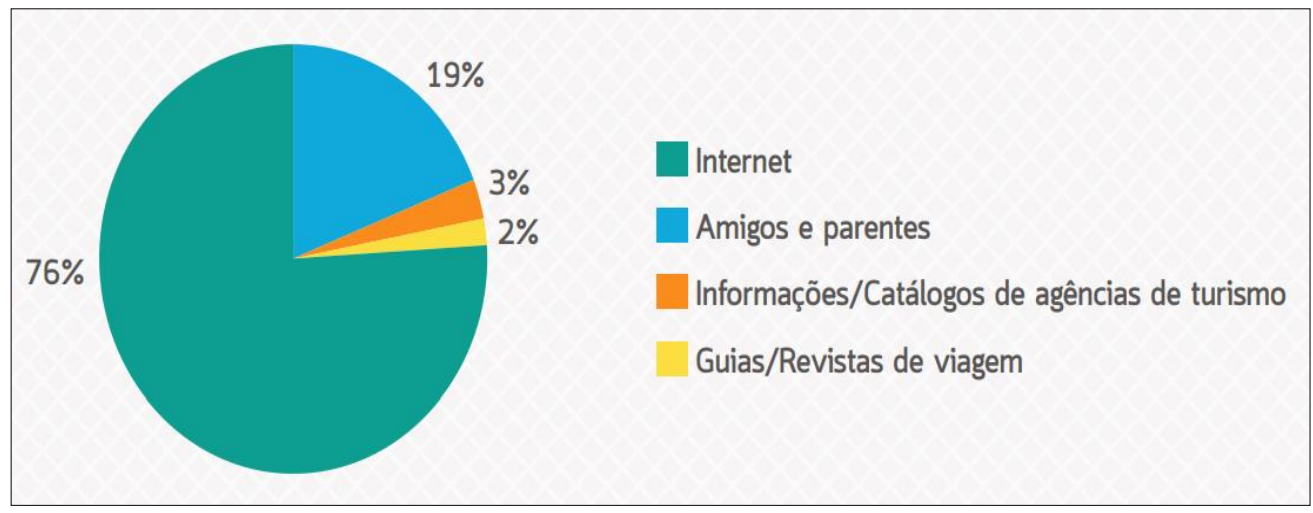

Fonte: SEBRAE, 2015; 2016

Compreende-se que esta nova geração não se influencia facilmente e o destino que se posiciona no mercado de forma tradicional passa despercebido aos olhos do novo turista. De acordo com Mangles (2017) o marketing tradicional não atrai mais, pois o novo turista está, quase sempre, conectado no smartphone e o que acontece ao seu redor desperta pouco interesse.

Toda essa alteração de valores faz com que o destino modifique suas estratégias de gestão e marketing, utilizando os sistemas de redes, buscando métodos inovadores, através de automatização de processos e tecnologia inteligente possa melhorar a experiência do visitante no destino. Esse perfil de turista busca a tecnologia wearable ${ }^{2}$, impressão 3D, os smartwatches ${ }^{3}$, a realidade aumentada, virtual e mista, os veículos autônomos e outros (BARCLAYS, 2018).

Essas novas perspectivas apontam para um perfil de visitante, cada dia mais frequente no destino de Porto Seguro e Arraial d'Ajuda, que busca nas mídias sociais as informações necessárias para escolher o destino visitado e também sendo a internet o meio preferido para realizar a compra, como apresentado no gráfico 2.

\footnotetext{
${ }^{2}$ Wearable é um termo que significa tecnologias para vestir. Trata-se de dispositivos eletrônicos e inteligentes que podem ser vestidos ou acoplados no corpo humano (CANAL TECH, 2019).

${ }^{3}$ São relógios inteligentes, eles realizam funções que vão além de mostrar as horas. São comparados com assistentes digitais pessoais. Suas principais funções são executar tarefas simples como cálculos matemáticos e tradução de palavras. No entanto, os relógios mais modernos são verdadeiros microcomputadores de pulso (TRANSFORMAÇÃO DIGITAL, 2019).
} 
Gráfico 2 - O meio mais utilizado para realizar a compra da viagem.

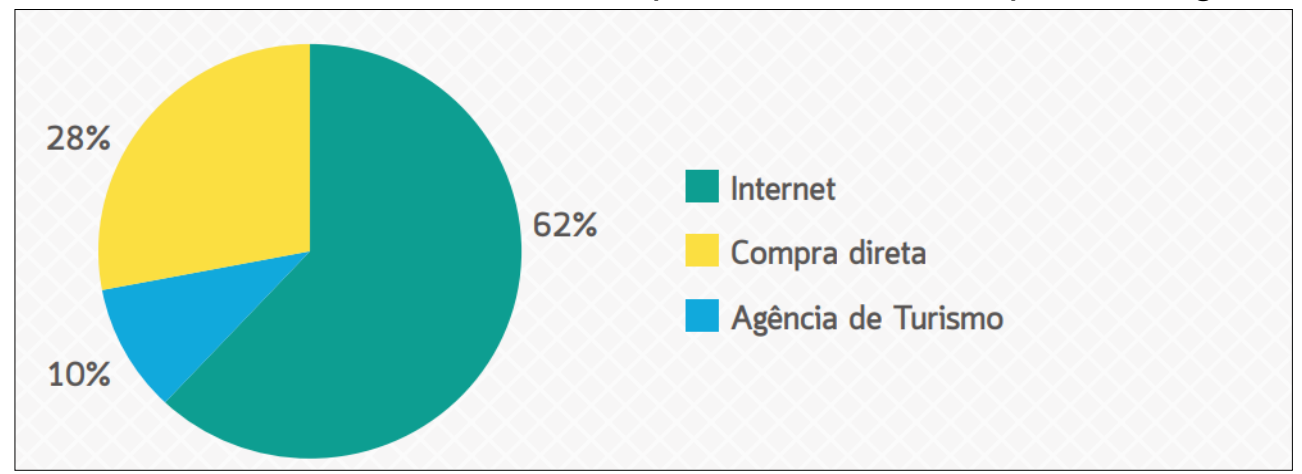

Fonte: SEBRAE, 2015; 2016.

Essas mudanças de comportamento social do indivíduo na sociedade moderna, através do modo de produção e consumo, têm sua estrutura montada na criatividade e no conhecimento, o que representa o desenvolvimento político, econômico e social do lugar ou da região (TRIGO; MAZARO, 2012). Nesse caso, o gestor do destino precisa ter conhecimento desses elementos que envolvem a atividade turística, sendo que é necessário analisar o espaço de forma macro, estudando a possibilidade de inter-relacionar os elementos, exigindo dessa gestão conhecimento e um olhar mais atento de todo o processo (SANTOS, 1997).

Neste contexto, desenvolvimento tecnológico, globalização, o reposicionamento do destino turístico e a competitividade são compreendidos como a capacidade de gerar lucros superando os concorrentes e de forma sustentável (PORTER, 1989). De acordo com Dwyer e Kim (2003) o que influencia o visitante escolher um determinado destino é principalmente os recursos básicos. Esses recursos podem ser naturais, que são a fauna e a flora, as condições de climas, a paisagem ou também, as características socioculturais da localidade como os costumes, a história, as manifestações e a gastronomia. De outra parte, outros recursos considerados elementares para o turismo é a infraestrutura turística, tais como, os transportes, os meios de hospedagens, entretenimento, eventos, entre outros (HEATH, 2003).

Além dos elementos citados acima, existem outros indispensáveis para estabelecer essa decisão. São os serviços de apoio, como o abastecimento de água, sistema de 
geração de energia elétrica, as estradas de acesso, telecomunicações, serviços de informática dentre outros (DWYER; KIM, 2003).

Outro ponto importante é a acessibilidade que inclui a facilidade dos acessos aos locais no destino, frequência e qualidade nos transportes coletivos, capacidade aeroportuária, das estações rodoviárias e estacionamentos públicos (BUHALIS, 2000).

É a partir da existência desses requisitos que o destino começa a se posicionar no mercado turístico. Porém, às vezes a infraestrutura e os elementos naturais e culturais do destino não são o suficiente para atender essa nova demanda, assim, uma alternativa para isso é fomentar por meio de políticas públicas ações e estratégias que visem o desenvolvimento do lugar a fim de que este se torne bom tanto para o turista quanto para o morador local.

Nesse sentido, para que um município venha a se tornar uma cidade inteligente, ou seja, uma SmartCity, o desenvolvimento deve estar relacionado a aplicação, o acesso e uso da tecnologia pelos usuários na cidade.

O termo Cidade inteligente (smartcity) pode ser compreendida por deferente forma, porém, entende como principal objetivo desse desenvolvimento a melhoria na qualidade de vida da comunidade local e, consequentemente, na vida do visitante.

Cidade inteligente é a visão holística de uma cidade que aplica a Tecnologia da Informação e Comunicação para a melhoria de qualidade de vida e acessibilidade de seus habitantes e garante um desenvolvimento com sustentabilidade econômica, social e ambiental em melhoria permanente. Uma cidade inteligente permite que cidadãos interajam com ela de forma multidisciplinar e adapta-se em tempo real às suas necessidades, de maneira eficiente de qualidade e custos, oferecendo dados abertos, soluções e serviços orientados para o cidadão como pessoas, para resolver os efeitos do crescimento da cidade, nas esferas pública e privada, para através da integração inovadora de infraestruturas com sistemas de gestão inteligente (BLANCO, 2015, p. 26). 
Assim que, o uso da tecnologia da informação está sempre presente e é a responsável em criar condições favoráveis no uso da infraestrutura da cidade, como organizar os serviços e recursos (HARRISON et al., 2010; WASHBURN et al., 2009).

Conforme apontam os autores Caragliu et al. (2011); Dameri, (2013) em relação ao turismo sustentável que por meio da utilização consciente dos recursos naturais desenvolve o crescimento econômico da cidade, como também, cria possibilidades de inclusão da comunidade local nas decisões referente ao uso desses recursos.

Já Bastos (2015) diz que a cidade inteligente se atenta a competitividade, o capital humano, a qualidade de vida, os recursos naturais entre outros fatores. Assim, surge a partir da necessidade de introduzir novas tecnologias buscando a princípio minimizar ou até resolver definitivamente os problemas de cidades, criando oportunidades de novos empregos e atraindo novos empreendedores. A definição de uma cidade inteligente envolve o aumento da Tecnologia da Informação e Comunicação - TCls (STIMMEL, 2015). Dessa forma cria-se um novo ambiente responsável em melhorar a performance da cidade por meio da utilização de serviços disponibilizados pelas TICs.

Outro ponto necessário a ser abordado é que as cidades inteligentes necessariamente precisam ser eficientes, porém, devem ser preservadas suas características, como a sociabilidade e espontaneidade dos seus moradores. Os novos modelos de cidade não podem perder sua identidade, pois deixaria de ser algo natural e passaria a ser algo automático.

Assim, Townsend (2013) afirma que é necessário combinar a infraestrutura com a tecnologia da informação, a arquitetura, os objetos e até mesmo com o próprio corpo dos moradores locais. Com base nos modelos de cidades inteligentes cria-se a possibilidade de transformação de destinos tradicionais em destinos turísticos inteligentes, que será apresentado e discutido no próximo item. 


\section{DESTINOS TURÍSTICOS INTELIGENTES (DTIS)}

Percebe-se que a economia mundial tem se globalizado, da mesma forma com o setor do turismo não poderia ser diferente, a globalização alcançou vários setores, de modo que, as informações de um local podem ser acessadas dos lugares mais distantes. Esse estreitamento possibilita o turista conhecer sobre o destino e atrativos de cada localidade, não importa onde essa pessoa esteja (LEMOS, 2001).

O setor do turismo está entre as atividades econômicas que lidera o comércio eletrônico a nível mundial, visto que, os aeroportos, os serviços de hospedagens, as agências de viagens são provas de que a TIC representa uma inovação, que provoca uma ruptura nos padrões de relacionamento entra a oferta e demanda turística (LÓPEZ DE ÁVILA et al., 2015).

Segundo Andrade (2018) é necessário que se faça uma reflexão em relação ao conjunto e os valores essenciais através das quais as pessoas exercem as diversas modalidades e os diferentes segmentos do turismo. Uma vez que, nem todas as atividades turísticas geram retorno econômico para a comunidade local, principalmente, quando se trata de turismo de massa.

A importância do Turismo na economia global em relação às questões sociais, ambientais e econômicas tem provocado modificações no desenvolvimento e planejamento do setor. Assim que, com o constante aumento das viagens, o viajante passou a ser mais consciente e sensível aos impactos causados pela atividade turística. A partir dessa perspectiva surge a necessidade de novas experiências, como a integração e a interação que são indispensáveis para se pensar em turismo responsável aliado ao desenvolvimento de um destino inteligente (LÓPEZ DE ÁVILA et al., 2015).

A maneira que o comportamento dos viajantes muda, altera se também, a relação com a viagem e o destino visitado. No mundo contemporâneo em que muitos estão hiperconectados, em que a internet se torna indispensável na prestação de serviços, 
os destinos turísticos buscam se adaptar a essas mudanças (IVARS-BAIDAL, SOLSONA-MONZONÍS, GINER-SÁNCHEZ, 2016).

De tal modo, López de Ávila et al., (2015) diz que a adaptação para a economia digital é o ponto chave para manter e aumentar a competitividade do destino turístico. Tanto o setor público que são os gestores, quanto o privado que são as empresas de diversos tipos devem se preparar para atender as necessidades dos turistas contemporâneos, ou seja, o viajante digital, bem informado e exigente. A acessibilidade por meio da tecnologia é a responsável para que o setor do turismo deixe de ser controlado pela oferta e passa a ser orientado pela demanda.

Seguindo o pensamento de López de Ávila et al., (2015) nesse novo cenário, o turista tem na palma das mãos, em pouco espaço de tempo, informações referentes aos serviços, produtos e preços, como também, disponibilidades e horários.

Para melhor entender o surgimento do conceito de Destinos Turísticos Inteligentes DTI, Smart Destination, devemos compreender que o conceito tem sua origem a partir das Cidades Inteligentes, Smart Cities (SEBRAE, 2016).

Pode-se dizer que as Cidades Inteligentes estão em um processo evolutivo o qual acelerou no século XXI, principalmente marcada pela chegada da internet 2.0. Com o aparecimento das novas tecnologias, os viajantes estão mais conectados, interativos e participativos (SEGITTUR, 2015).

O conceito de DTI surgiu em 2012, na região da Catalunha, Comunidade Autônoma da Espanha. Contudo, foi em março de 2013 que a Sociedad Mercantil Estatal para la Gestión de la Innovación y las Tecnologías Turísticas - SEGITTUR lançou o 5o Subcomité denominado "Destinos Inteligentes" o qual teve como objetivo criar normas de Destinos Turísticos Inteligentes, assim, foi desenvolvido um sistema de indicadores para facilitar a medição e unificação de critérios dos DTIs (SEGITTUR, 2018). 
Dos critérios necessários para ser considerado um DTI destacar-se a importância dos dados no processo de desenvolvimento de um turismo inteligente, nos ecossistemas digitais que consiste em tecnologias que facilitam o dia a dia e na elaboração de experiências (GRETZEL et al., 2015).

Um DTI precisa ter uma flexibilidade para se ajustar a sua demanda. Entretanto, somente oferecer produtos que satisfaça a sua demanda não é o suficiente. O uso das novas tecnologias é indispensável para a geração de dados, que os gestores compreendam sua demanda real e utilizem as mídias digitais, como as redes sociais, em uma constante interação entre o destino, a gestão e o turista (FERMENIA-SERRA; CELDRÁN-BERNABEU; IVARS-BAIDAL, 2016).

De acordo com a Segittur (2015) o DTI se define como um local inovador que deverá proporcionar acessibilidade, infraestrutura tecnológica que garanta a sustentabilidade do território, aproximando e interagindo o visitante com o ambiente, assim como, explorando o potencial do destino e melhorando a qualidade de vida dos moradores.

Para diferenciá-lo dos destinos tradicionais, o DTI possui características como a integração e interação antes do visitante chegar ao destino, durante a estadia e se estende depois de sua partida; é importante que a governança seja compartilhada com outros setores e atores; os limites geográficos podem ou não corresponder com os limites do município; ligados à competitividade e melhoria da experiência do turista em um espaço inovador, entre outras (SEGITTUR, 2015).

De acordo com a Segittur (2015) esse espaço inovador traz benefícios que são produzidos por meio das tecnologias aplicadas no território turístico. Dessa forma, a melhoria da Cidade Inteligente influencia a qualidade de vida dos cidadãos, que por sua vez, beneficia o DTI. Logo, percebe-se que a caracterização entre Cidade Inteligente e DTI tem objetivos distintos, já que, no DTI é voltado o turista e na Cidade Inteligente para população local (LUQUE GIL; ZAYAS FERNÁNDEZ; CARO HERRERO, 2015). 
O significado de DTI é recente e o seu conceito ainda não foi definido completamente, devido aos recentes debates referentes à sua existência (DEL CHIAPPA; BAGGIO, 2015). Em relação ao seu conceito, tem destaque a contribuição espanhola, sendo a precursora na normatização e definição dos DTls (BLANCO, 2015; LOPEZ DE AVILA; GARCÍA SÁNCHEZ, 2013).

É sabido que a ideia de DTI surge do conceito de cidade inteligente, embora, não devemos associar-se tão somente ao modelo das cidades inteligentes, uma vez que há uma série de outras alterações estruturais no setor do turismo as quais justificam a necessidade de novos aspectos na gestão dos destinos, como por exemplo, as mudanças proporcionadas pelas novas tecnologias e globalização (INVATTUR, 2015).

Sobre outra perspectiva, o termo "inteligente" pode ser utilizado na própria atividade em si. Logo, o turismo inteligente estaria um passo a frente do turismo tradicional, progredindo para uma atividade mais orientada na inovação e no desenvolvimento das TCls, que dependem dos dados (big data e open data), novos meios de conectividades e troca de informações (GRETZEL et al., 2015).

O desenvolvimento de ambos os aspectos tecnológicos em torno de um destino turístico tem um elo comum: a informação. Com a era da comunicação digital e móvel, a comunicação entre os equipamentos eletrônicos por meio de sensores aponta uma interação do visitante com o destino através das redes sociais e o uso intensivo de tecnologias gera um volume de dados necessários para armazenar, analisar e gerenciar melhor o seu aproveitamento (LÓPEZ DE ÁVILA et al., 2015).

De acordo com Blanco (2015) para chegar nesse melhor aproveitamento são utilizados novos modelos de gestão da informação, como a plataforma big data, que tem um papel fundamental e a capacidade de obter e gerenciar conhecimento e esses dados são ajustados para os seguintes parâmetros: Volume: grande quantidade de dados que são atualizados frequentemente; Variabilidades de dados 
e fontes: Diferentes informações por diversos canais; Velocidade do processamento: ferramentas de análises, dados em tempo real; Valor de negócio: Vantagens competitivas em diversas áreas, como governança, segurança, mobilidade, saúde, relacionamento com o turista e outros; Veracidade: a confiabilidade dos dados, a quantidade de informação e sua precisão. O sistema tem a capacidade de analisar, de forma inteligente, uma grande quantidade de dados, oferecendo informações verdadeiras e úteis as quais auxiliam no poder de decisão do viajante (CHEN et al. 2014; DEMCHENKO et al., 2014).

\section{PROCESSO PARA TRANSFORMAR UM DESTINO CONSOLIDADO EM DTI}

Quando se estuda a possibilidade de converter um destino turístico tradicional em um DTI é necessário entender os efeitos que esse processo poderá ocasionar.

A finalidade de converter um destino turístico em destino turístico inteligente é desenvolver uma estratégia de revalorização por meio da tecnologia e inovação, dessa forma, cria-se mecanismo que permite aumentar sua competitividade, aproveitando os recursos turísticos ou identificando e criando outros; também, aprimorando a eficiência dos processos de comercialização e produção com ações sustentáveis, melhorando a qualidade da estadia dos visitantes e a qualidade de vida dos residentes (LÓPEZ DE ÁVILA; GARCIA, 2013).

A Segittur (2015) aponta a importância das tecnologias e da inovação na formação de um DTI e reconhece também que é fundamental incluir outros elementos como a governança, a acessibilidade, a sustentabilidade e os residentes. Contudo, se discute que ainda há dificuldades para medir como um destino é considerado, de fato, inteligente de acordo com o conceito. Essa complexidade e diversidade do DTI requer uma atuação do poder público e privado em parceria com as entidades de formações para elaborar e desenvolver um plano de ação em conjunto que envolva outros aspectos e que não fique restrito somente ao setor do turismo, mas igualmente ao setor econômico, tecnológico, ambiental, cultural, entre outros (LÓPEZ DE ÁVILA; GARCÍA, 2013). 
Dessa forma, o destino pode ter, em um curto espaço de tempo, o aumento da competitividade e assim, melhorar a eficiência nos processos de como produzir e a forma de comercialização. $E$ isso pode refletir em todos os setores do destino (SEGITTUR, 2015).

Para o processo de transformação de um destino é necessário conhecer tecnologias da informação e comunicação que é um dos fatores principais para a evolução de um destino aliado ao trabalho de marketing poderá contribuir para a promoção desses locais, como também, as redes sociais, já que estas geram uma quantidade de dados significativos que poderão ser utilizados para o aperfeiçoamento do trabalho dos gestores de um DTI (THOMAZ; BIZ; GÂNDARA, 2013).

uso de mídias sociais, realidade aumentada, big data, sensores e diversos outros processos elevam o turismo ao topo da sociedade digital, modificando e elevando as relações entre os atores dentro da atividade, compreende-se que não há como falar sobre desenvolvimento inteligente sem o auxílio das TCls que evoluíram e fazem parte da atividade turística. O viajante digital busca conhecer e explorar o destino consciente, de forma sustentável e visitar atrativos diferentes do que o turista comum está acostumado. Assim, se o perfil do turista muda, se modifica também a prestação de serviço e os produtos (LÓPEZ DE ÁVILA et al., 2015).

O setor do turismo está se reestruturando, para se adaptar ao novo perfil do turista hiperconectado e interativo, disponibilizando através de serviços, produtos e experiências mais integradas e personalizadas. $E$ isso só é possível devido ao surgimento de novas tecnologias, principalmente, a internet e os dispositivos móveis, que vem impulsionando os novos modelos de negócios turísticos que conduzem o visitante nas três fases da viagem apontadas pela SEGITTUR (2015), conforme se apresenta a seguir:

Fase 1 - $O$ antes (a inspiração assistida): o acesso a uma vasta quantidade de dados, estruturados sobre destinos, produtos e serviços enriquece 
consideravelmente a capacidade de escolha do turista. Fase 2 - O durante (a mobilidade inteligente): o aumento da conectividade nos destinos, o crescente uso da tecnologia e aplicações de mobilidade torna mais fácil e flexível a experiência turística, o viajante interage a todo o momento tanto com os fornecedores de produtos e serviços como com outros turistas conectados, que dessa forma, pode tomar decisões mais inteligentes sobre o destino. Fase 3- O depois (a satisfação compartilhada): o desafio principal das empresas e dos destinos é saber onde, como e quem fala de seus produtos e serviços, existe diversas aplicações da comunicação interativa, em especial as redes sociais, que é possível conhecer o nível de satisfação dos turistas e aplicar sistemas de melhoria contínua, assim, desenvolver novos sistemas de fidelização.

Para que um DTT se converta em DTI foram criadas diretrizes de ação que são utilizadas por entidades gestoras de destinos competentes em matéria de inovação, tecnologia, acessibilidade e sustentabilidade. Esse é o primeiro passo para a transformação de um destino em DTI. Segundo passo, a vontade de mudar. É necessário estar disposto a evoluir e desenvolver uma estratégia concreta e dispor de recursos para a sua execução, tanto por parte do poder público quanto do privado, lembrando um dos pontos principais, a participação da comunidade (SEGITTUR, 2015).

Em seguida, deve começar um relatório de diagnóstico apontando as necessidades em diferentes áreas do município e determinar as intervenções necessárias, tal como, os elementos reguladores e de planejamento que são necessários para a sua implementação (LÓPEZ DE ÁVILA et al., 2015). O quadro 1 aponta os quatros eixos fundamentais para que um destino turístico inteligente se estabeleça:

Quadro 1 - Categorias e indicadores de DTIs.

\begin{tabular}{|c|l|}
\hline \multicolumn{1}{|c|}{ EIXOS } & \multicolumn{1}{c|}{ INDICADORES } \\
\hline \multirow{3}{*}{ INOVAÇÃO } & $\begin{array}{l}\text { Troca de conhecimentos; } \\
\text { Desenvolvimento de novos serviços ou produtos } \\
\text { melhorados; } \\
\text { Desenvolvimento de novos métodos e processos; } \\
\text { Desenvolvimento de novos modelos de negócio; }\end{array}$ \\
\hline
\end{tabular}




\begin{tabular}{|c|l|}
\hline TECNOLOGIA & Novas formas de organizações públicas e privadas. \\
\hline ACESSIBILIDADE & $\begin{array}{l}\text { Captação de análise de dados; } \\
\text { Promoção e comunicação online, por meio de site oficial } \\
\text { Desenvolvimento de dispositivos móveis; } \\
\text { Implementação de Wi-Fi nos espaços públicos; } \\
\text { Open Data e Automatização de processos e soluções } \\
\text { que envolva tecnologia. }\end{array}$ \\
\hline $\begin{array}{l}\text { Facilitar o acesso da comunidade e turistas a espaços } \\
\text { públicos e locais de interesse turísticos; } \\
\text { Facilitar o acesso da comunidade e turistas à } \\
\text { informação; } \\
\text { Facilitar o acesso da comunidade e turistas a serviços } \\
\text { urbanos e turísticos. }\end{array}$ \\
\hline $\begin{array}{l}\text { Sustentabilidade ambiental - manutenção dos recursos } \\
\text { ambientais; eficiência energética; coleta e separação do } \\
\text { lixo; saneamento; mobilidade urbana; meio de } \\
\text { transportes alternativos; } \\
\text { Sustentabilidade sociocultural - co-criação; } \\
\text { planejamento participativo; preservação dos aspectos } \\
\text { culturais locais; relacionamento entre turista e } \\
\text { comunidade autóctone; } \\
\text { Sustentabilidade econômica - distribuição dos benefícios } \\
\text { econômicos; promoção e comercialização de produtos } \\
\text { sustentáveis do comercial e artesanato local. }\end{array}$ \\
\hline SUSTABILIDADTa
\end{tabular}

Fonte: SEGITTUR, 2015. Org.: COSTA, 2019.

De acordo com o quadro 1, a inovação estabelece o eixo central na transformação de um destino. O destino turístico que não se adequar as novas necessidades dos visitantes está um passo atrás dos demais, perdendo seu posicionamento no mercado, sendo que inovar no turismo implica a busca por novos modelos de gestão, formas de comunicação, o bem-estar do turista, dos moradores e o mais importante é que a inovação traga a busca por melhorias contínuas, de modo a enfrentar o mercado do turismo que está cada dia mais globalizado (LÓPEZ DE ÁVILA et al., 2015). 
A ideia de inovação no DTI é buscar em seus serviços e produtos algo que agrega valor. Uma oferta turística diferenciada, um upgrade para o turista, facilidades no acesso em ambientes como museus, reservas ecológicas e comunidade local. Dessa forma, desenvolve a promoção e distribuição de serviços e cria-se o anseio por novos produtos (LÓPEZ DE ÁVILA et al., 2015).

Portanto, o DTI não está ligado somente com a informatização, mas quando é encaminhado para a transformação do turista, converge também para a produção de novas experiências, a partir de um conjunto de valores. A tecnologia surge com um papel relevante no desenvolvimento de um DTI, sobretudo relacionado a toda rede com a atividade do turismo (NEUHOF; BUHALIS; LADKIN, 2012; 2015).

Observa-se que nos dias atuais a tecnologia é uma ferramenta indispensável de comunicação para a gestão de empresas e que não beneficia somente o turista, como também, os próprios residentes do destino. A criação de uma solução de mobilidade integral tem como objetivo facilitar a integração do visitante com o destino, por meio de diferentes tecnologias (wi-fi, iBaicons ${ }^{4}$ ), as quais possibilitam a conexão e o fluxo de informação por meio de diversos dispositivos (sites e aplicativos). Uma oportunidade de aumentar a produtividade das organizações, assim o visitante passa a ter uma melhor percepção da qualidade do destino, com informações a qualquer hora e lugar (LÓPEZ DE ÁVILA et al., 2015).

Entre as diversas propostas que envolvem a tecnologia aplicada no DTI, cita-se algumas, tais como: Web 2.0; Cloud computing ou nuvem; Big data; Internet of things; Apps; Código Qr (QrCode) e Open data.

Outro ponto de discussão é o estágio de aceitação real em relação à resistência da inserção de novas tecnologias. Mesmo entendendo que o visitante tem uma boa

\footnotetext{
${ }^{4}$ São dispositivos de geolocalização para ambientes fechados, ou seja, é um sistema de proximidade. Sendo assim, o Beacon permite que objetos como smartphones sejam localizados com uma alta precisão dentro de estabelecimentos.
} 
relação com o mundo tecnológico, é importante refletir sobre os prováveis problemas de dependência tecnológica. $O$ uso exagerado dessas ferramentas pode levar a futuros problemas como a saturação de informação e a redução de espontaneidade na concepção e condução da experiência turística (GRETZEL, 2011).

Uma das grandes dificuldades enfrentadas pelos visitantes em Porto Seguro é a falta de acessibilidade. Inúmeras pessoas por razões de idade, gravidez ou por alguma inaptidão que comprometa a mobilidade são privadas de acesso à atividade turística, já que, na maioria das vezes, as infraestruturas são inadequadas e os equipamentos não apresentam condições apropriadas às suas necessidades.

O DTI tem esse desafio de modificar esse cenário para que as propostas permitam a acessibilidade ao máximo de visitantes e residentes, tanto para o destino, como também, para os seus produtos e serviços. Portanto, é imprescindível que o DTI torna-se satisfatório para o visitante quanto para o morador (LÓPEZ DE ÁVILA et al., 2015).

É importante lembrar que, a acessibilidade em um DTI vai além da mobilidade urbana. Neste sentido, outro desafio é a acessibilidade digital, desenvolver adaptações em seu material digital, como em suas páginas na internet, promover análise nas infraestruturas urbanas que tem forte impacto no setor turístico, aeroportos, rodoviárias, espaços públicos, entre outros. A participação de agentes profissionais do setor é um ponto chave desse eixo, assim como, a realização de campanhas de conscientização e sensibilização do público residente e serviços de informação, painéis ou aplicativos para atender pessoas com deficiência visual.

Outro eixo em estudo é a sustentabilidade que apresenta ações contínuas como a capacidade de carga do território, a preservação de meio ambiente e sociocultural, da mesma forma, o desenvolvimento econômico para aumentar a qualidade de vida da população local, melhorar a experiência do visitante (BLANCO, 2015). 
Assim que, é preciso analisar a sustentabilidade com diversos olhares. O lado empreendedor que busca negócios economicamente sustentáveis; o cultural que procura novas estratégias que provocam a imersão do visitante nos costumes e na história de cada povo; e, o social, ter o cuidado com que a comunidade local não veja o turista como um invasor, assim, não se posicionando contra (LÓPEZ DE ÁVILA et al., 2015).

\section{METODOLOGIA}

A pesquisa se classifica como descritiva e exploratória com natureza qualitativa, posto que após o levantamento dos dados foi feita a análise sobre as informações coletadas. As pesquisas descritivas visaram estudar as características e também correlacionar variáveis determinando a natureza da relação entre elas proporcionando uma visão nova do problema. No mesmo sentido, a pesquisa exploratória tem como finalidade a proximidade com 0 assunto analisado normalmente utilizando estudo de caso com amostragens qualitativas (GIL, 2008).

Quanto aos procedimentos técnicos foi utilizado o bibliográfico, documental e levantamento de dados através de uma observação direta sistemática. 0 bibliográfico por utilizar materiais já publicados: livros, monografias e artigos científicos. O documental, especialmente documentos oficiais emitidos pela Prefeitura Municipal de Porto Seguro. Já observação direta sistemática consistiu em ir a campo para identificação e analise dos elementos da infraestrutura necessários para transformação do destino de Porto Seguro em DTI. Para isso utilizou-se o quadro síntese das categorias e indicadores de destino turístico inteligente modelo da SEGITTUR.

É importante apontar que o objetivo não foi aprofundar o conhecimento sobre cada parâmetro fornecido pela SEGITTUR através dos quatro eixos apresentados anteriormente, mas identificar os eventos que impactam ou são impactados por esses parâmetros. 
No distrito de Arraial d'Ajuda foi selecionado o Centro Histórico por possuir parâmetros definidos pelo Instituto do Patrimônio Histórico e Artístico Nacional IPHAN a Praça São Brás, Praça do Cemitério, Rua Santa Rita, Praça Brigadeiro Eduardo Gomes e Rua Bela Vista, a estrada da balsa e a Rua do Mucugê.

Já em Porto Seguro (Sede) foi determinado o Centro Histórico que é constituído pela Cidade Alta, Outeiro da Glória ao norte, Rio do Vila ao sul, Margens esquerda da BR 367 até o trevo de acesso a Santa Cruz Cabrália, a Cidade Histórica, o aeroporto internacional, o terminal da balsa, a rodoviária municipal, a área histórica da cidade baixa e o conjunto da Passarela do Descobrimento.

O motivo da escolha desses locais se deu em virtude de apresentarem fluxo maior de visitantes e residentes nesses pontos, ficando assim, viável a observação direta, dando consistência para a pesquisa e para o diagnóstico com as proposições em forma de diretrizes.

Quanto aos locais da pesquisa, no Distrito de Arraial d'Ajuda no Centro Histórico foi observado: a existência de estacionamento público, a padronização das calçadas e rampas de acesso, rede wi-fi gratuita e lixeiras seletoras. Na Estrada da Balsa observou: a padronização das vias e das calçadas, a iluminação púbica, câmeras de monitoramentos e os itinerários dos transportes coletivos. Na Rua do Mucugê foi verificada: a padronização das calçadas e rampas de acesso, coleta do lixo e lixeiras seletoras e centro de informação ao turista.

Em Porto Seguro (sede) na Cidade Histórica foi verificado: a presença de estacionamento público, vagas reservadas para carros de pessoas com necessidades especiais, lixeiras seletoras, rede wi-fi gratuita e câmera de monitoramento. Já no aeroporto, na rodoviária e no terminal das balsas foram observados: rampas de acesso, vagas para pessoas com necessidades especiais, a disponibilidade do uso dos equipamentos totens, rede wi-fi gratuita, centro de informação ao turista e piso tátil de alerta e direcional. Por fim, na Passarela do Descobrimento foi verificado: a padronização das calçadas e rampas de acesso, 
rede wi-fi gratuita, lixeiras seletoras, a iluminação púbica, câmeras de monitoramentos, pontos de ônibus e os itinerários dos transportes coletivos.

\section{PROPOSTA DO MODELO SEGITTUR A SER APLICADO EM PORTO SEGURO}

A partir das análises realizadas acredita-se que o Município de Porto Seguro apresenta potencial para que venha a ser um DTI, no entanto, necessita rever a infraestrutura e equipamentos existentes para se adequar aos requisitos de um DTI conforme os exemplos descritos nesse trabalho. Assim que, as diretrizes que ora serão apresentadas no quadro 2 são sugestões para que o Município de Porto Seguro possa se alinhar a um DTI.

Quadro 2 - Diretrizes propostas para o município de Porto Seguro

\begin{tabular}{|l|l|}
\hline Diretriz 1 & O Airbnb como economia colaborativa \\
\hline Diretriz 2 & $\begin{array}{l}\text { Sistema de sensores para o gerenciamento do tráfego, segurança e } \\
\text { iluminação pública }\end{array}$ \\
\hline Diretriz 3 & Elaboração do Aplicativo (App) do destino \\
\hline Diretriz 4 & Meios de locomoção e Sistema de GPSs no transporte público \\
\hline Diretriz 5 & Centros de informações digitais \\
\hline Diretriz 6 & Dados abertos da demanda e perfil do turista \\
\hline Diretriz 7 & Utilização das redes sociais na promoção do destino \\
\hline Diretriz 8 & Internet sem fio gratuita nos espaços públicos \\
\hline Diretriz 9 & Distribuição de totem pelos principais pontos da cidade \\
\hline Diretriz 10 & $\begin{array}{l}\text { Políticas públicas eficientes de preservação e manutenção dos recursos } \\
\text { ambientais }\end{array}$ \\
\hline Diretriz 11 & Transporte coletivo alternativo \\
\hline Diretriz 12 & Planejamento participativo \\
\hline Diretriz 13 & $\begin{array}{l}\text { Comercialização de produtos sustentáveis do comercial e artesanato } \\
\text { local }\end{array}$ \\
\hline Diretriz 14 & $\begin{array}{l}\text { Programa de mobilidade urbana e acessos para pessoas com } \\
\text { deficiência (PcD) }\end{array}$ \\
\hline Diretriz 15 & Existência de piso tátil de alerta e direcional \\
\hline Diretriz 16 & Melhoria dos estacionamentos na via pública \\
\hline Diretriz 17 & $\begin{array}{l}\text { Comunicação rápida com os serviços de assistência médica e de } \\
\text { segurança pública }\end{array}$ \\
\hline Diretriz 18 & $\begin{array}{l}\text { Equipamentos de conforto junto aos espaços culturais e de recreação } \\
\text { com grande concentração de público }\end{array}$ \\
\hline
\end{tabular}

Fonte: COSTA, 2020. 
A necessidade desses equipamentos faz parte dos serviços da infraestrutura turística e auxilia na satisfação do turista, bem como viabiliza a vida do morador local que se desloca nesses locais. É necessário implantar estruturas permanentes para promover melhor qualidade de vida e a sustentabilidade da cidade. Não somente a construção de banheiros públicos e bebedouros, como também, a melhoria das condições de iluminação, banco modulares e arborização configuram um espaço mais atraente e seguro, o que contribuiria para a sociabilização entre os usuários o que poderá proporcionar uma interação entre os turistas e a comunidade local.

\section{CONSIDERAÇÕES FINAIS}

Esse trabalho consistiu em analisar o potencial do destino de Porto Seguro com possível transformação para destino turístico inteligente utilizando as diretrizes da Segittur como critérios de análise. Com o afloramento dos Destinos Turísticos Inteligentes no Brasil, a possibilidade de apresentar o destino de Porto Seguro inteligente surge como um fator significativo e uma estratégia de elevar a imagem da cidade em meio aos destinos concorrentes.

A partir das informações observou-se que o Município de Porto Seguro ainda não tem uma gestão voltada aos eixos propostos pelo SEGITTUR, para que o destino se torne um DTI. O principal resultado encontrado em relação ao potencial do município de Porto Seguro para uma possível transformação em DTI foi que o destino dispõe de infraestrutura e equipamentos que possivelmente podem adequar-se ao modelo de DTI. Sendo que, seria substancial a reestruturação, tendo em vista, a implementação de equipamentos tecnológicos para se iniciar o processo de transformação.

Compreende-se que as principais ações dependem da iniciativa do poder público municipal, pois estão ligadas ao planejamento e aos investimentos. Cabe dizer que embora seja uma iniciativa da gestão pública, seria imprescindível a participação da iniciativa privada, das Ongs e da comunidade local para que o processo de transformação em DTI envolva os atores sociais. 
Também é de suma importância conhecer a realidade do município, suas limitações e potencialidades tanto econômicas, quanto sociais e culturais almejando uma transformação socialmente justa, economicamente responsável e ambientalmente correta.

Assim que, a infraestrutura identificada tanto na sede quanto no distrito de Arraial d'Ajuda, tais como, o estacionamento público, rampas e calcadas, rede wi-fi, iluminação pública, segurança, transporte público, lixeiras, totem, pontos de ônibus necessitam de melhorias e/ou reparos para que estejam habilitados para serem utilizados por moradores e turistas.

Entre os estudos das análises apresentadas, tanto para o Município de Porto Seguro quanto ao distrito de Arraial d'Ajuda, entende-se que as diretrizes que estão presentes são: Diretriz 1; Diretriz 6; Diretriz 7; Diretriz 10; Diretriz 12; Diretriz 14; Diretriz 16 e Diretriz 17. Já as que não se confirmaram são: Diretriz 2; Diretriz 3; Diretriz 4; Diretriz 5; Diretriz 8; Diretriz 9; Diretriz 11; Diretriz 13; Diretriz 15 e Diretriz 18.

Acredita-se que a hipótese foi confirmada parcialmente já que a infraestrutura e serviços existentes necessitam de melhorias para que venham de fato a atender aos eixos propostos pela SEGITTUR e demais exemplos de DTI apresentados no decorrer deste trabalho.

Por fim, com fundamento no que foi exposto nesse trabalho entende-se que 0 Município de Porto Seguro a partir do recorte territorial realizado, tem potencialidade para vir a transformar-se em um Destino Turístico Inteligente na Costa do Descobrimento. No entanto enfatiza-se sobre as diretrizes/ sugestões aqui apresentadas para que aliadas a um trabalho árduo, contínuo e em conjunto entre a gestão pública, empresas e comunidade local venha a ser uma realidade e Porto Seguro possa tornar-se um DTI. 


\section{REFERÊNCIAS}

ANDRADE, José Vicente de. Turismo: fundamentos e dimensões. 7 ed. Ed. Ática. p. 9. São Paulo, 2000.

BARCLAY. A. Summary of Talking About My Generation: Exploring the Benefits Engagement Challenge. Disponível em: www.barclays.com/employersolutions. Acesso em 26 de fev. de 2018.

BASTOS H. Z. L. Análise de desempenho e projeto de uma infraestrutura de cidade inteligente para transporte público de Curitiba. Dissertação (Mestrado em Informática) - Setor de Ciências Exatas, Universidade Federal do Paraná, Curitiba, 2015. Disponível em: http://acervodigital.ufpr.br/handle/1884/40987. Acesso em 17 mar. 2020.

BENI, Mário Carlos. Análise Estrutural do Turismo. São Paulo: SENAC, 1998.

BLANCO, J. Libro blanco de los destinos turísticos inteligentes: estratégias y soluciones para fomentar la innovación em el turismo digital. Madrid, Espanha: LID Editorial Empresarial, 2015.

BUHALIS, D. Marketing the competitive destination of the future. Tourism Management, 2000.

CANALTECH. Os Wearables são a evolução da tecnologia movel. Disponível em: $<$ https://canaltech.com.br/produtos/os-wearables-sao-a-evolucao-da-tecnologiamovel/>. Acesso em: 23 Dez. 2019.

CARAGLIU, A.; DEL BO, C.; NIJKAMP, P. "Smart cities in Europe". Journal of urban technology, 2011.

DAMERI, R. P. "Searching for smart city definition: a comprehensive proposal". International Journal of Computers \& Technology, 2013. Disponível em: < https://www.researchgate.net/publication/283289962_Searching_for_Smart_City_defi nition_a_comprehensive_proposal>. Acesso em 17 mar. 2020.

DWYER, L.; Kim, C. "Destination Competitiveness: Determinants and Indicators". Current Issues in Tourism, 2003. Disponível em: <

https://www.researchgate.net/publication/228777665_Destination_Competitiveness_ Determinants_and_Indicators >. Acesso em 17 mar. 2020.

GIL, A. C. Métodos e técnicas de pesquisa social. 6 ed. São Paulo: Atlas, 2008.

GRETZEL, U.; SIGALA, M.; XIANG, Z; KOO, C. "Smart tourism: foundations anddevelopments". Electronic Markets, v. 25, n. 3, p. 179-188, 2015. Disponível em: $<$ https://www.researchgate.net/publication/280719315_Smart_tourism_foundations_a nd_developments>. Acesso em 17 mar. 2020. 
HARRISON, C., et al., P. "Foundations for smarter cities". IBM Journal of Research and Development, 2010. Disponível em:

<https://ieeexplore.ieee.org/document/5512826>. Acesso em 17 mar. 2020.

HEATH, E. "Towards a model to enhance Africa's sustainableTourism Competitiveness", Public Administration, 2003. Disponível em:

<https://repository.up.ac.za/bitstream/handle/2263/5439/Heath_Towards\%282002\%2 9.pdf?sequence=1>. Acesso em $17 \mathrm{mar}$. 2020.

INVATTUR. Agència Valenciana del Turisme. Destinos Turísticos Inteligentes. 2015. Disponível em: <http://pt.slideshare.net/invattur/manual-operativo-para-laconfiguracin-de-destinos-inteligentes>. Acesso em 17 mar. 2020.

IVARS BAIDAL, J. A.; SOLSONA MONZONÍS, F. J. \& GINER SÁNCHEZ, D. "Gestión turística y tecnologías de la información y la comunicación (TIC): El nuevo enfoque de los destinos inteligentes". Documents d'Anàlisi Geogràfica, 2016.

LEMOS, Leandro de. Turismo: que negócio é esse? $3^{a}$ ed. Campinas, São Paulo: Papirus, 2001.

LOPEZ DE AVILA. Á; GARCÍA SÁNCHEZ, S. "Destinos Turísticos Inteligentes". Harvard Deusto Business Review, n. 224, p. 58-67, 2013. Disponível em: <https://www.harvard-deusto.com/destinos-turisticos-inteligentes>. Acesso em 17 mar. 2020.

LUQUE GIL, A. M.; ZAYAS FERNÁNDEZ, B.; CARO HERRERO, J. L. "Los Destinos Turísticos Inteligentes en el marco de la Inteligencia Territorial: conflictos y oportunidades". Investigaciones Turísticas, v. 10, p. 1-25, 2015. Disponível em: <https://rua.ua.es/dspace/bitstream/10045/52102/1/Investigaciones_Turisticas_10_0 1.pd $\mathrm{f}>$. Acesso em: 17 set 2018.

MANDER, J. Get to know Gen Z. "Trends 18 Trends to know for 2018". Globalwebindex, 2018. Acesso em 17 mar. 2020. Disponível em: $<$ https://cdn2.hubspot.net/hubfs/304927/resources-page/Content/Trends-18.pdf>. Acesso em 10 mar. 2020.

MONACO, S. "Tourism and the new generations: emerging trends and social implications in Italy". Journal of Tourism Futures. 2018. Disponível em: <https://doi.org/10.1108/JTF-12-2017-0053>. Acesso em 17 mar. 2020.

NEUHOFER, B.; BUHALIS, D.; LADKIN, A. Conceptualising technology enhanced destination experiences. Journal of Destination Marketing \& Management, v. 1, n.1-2, p. 36-46, 2012. Disponível em:

$<$ https://barbaraneuhofer.com/2017/11/27/conceptualising-technology-enhanceddestination-experiences/>. Acesso em 17 mar. 2020.

PORTER, M. Vantagem competitiva. 18 ed. Rio de Janeiro: Campus, 1989. 
SANTOS, M. A natureza do espaço: técnica e tempo, razão e emoção. $2^{2}$ ed. São Paulo: HUCITEC, 1997.

SEBRAE. Serviço Brasileiro de Apoio às Pequenas e Micro Empresas. Destinos Turísticos Inteligentes. Disponível em:

http://www.sebrae.com.br/sites/PortalSebrae/Busca?q=Destinos\%20Tur\%C3\%ADsti cos\%20Inteligentes. Acesso em: 05 Abril 2019.

SEGITTUR. Informe destinos turísticos inteligentes: construyendo el futuro. Madrid, Relatório. 2015. Disponível em:

http://www.segittur.es/opencms/export/sites/segitur/.content/galerias/descargas/docu mentos/Libro-Destinos-Inteligentes-en-Espaol.pdf. Acesso em 17 Jan. 2019.

STIMMEL, C. L. Building smart cities: analytics, ICT and design thinking. Boca Raton: Auerbach Publications, 2015.

THOMAZ, G. M., Biz, A. A., Gândara, J. M. G. "Innovación en la promoción turística en medios y redes sociales: Un estudio comparativo entre destinos turísticos". Estudios y Perspectivas en Turismo, 2013. Disponível em: <https://www.redalyc.org/articulo.oa?id=180725735006>. Acesso em 20 Jun. 2019.

TOWNSEND, A. M. Smart cities: big data, civic hackers and the quest for a new utopia. New York: W. W. Norton \& Company, 2013.

TRANSFORMAÇÃO DIGITAL. "Smartwatches". Transformação Digital, 2019.

Disponível em: <https://transformacaodigital.com/?s=smartwatches\&t=post>. Acesso em 23 Dez. 2019.

TRIGO, L.G.G.; Mazaro, R. Movimentos globais e cenários em turismo: Uma realidade dinâmica, uma viagem ao futuro. Turismo em Análise, 2012.

WASHBURN, D., et al., Helping cios understand "smart city" initiatives. Growth, 2009.

WE ARE SOCIAL. Digital in 2016. We Are Social, 2016. Disponível em: $<$ https://wearesocial.com/uk/special-reports/digital-in-2016>. Acesso em 25 Jun. 2019. 